\title{
"Good death" - the circumstances in which it would be best for a person to die. The representative survey of Latvian population
}

\author{
Diana Kalnina ${ }^{1,2}$ and Ilva Skulte ${ }^{2}$ \\ ${ }^{1}$ Riga Stradins University, Statistics Unit of Faculty of Medicine, Riga, Latvia \\ ${ }^{2}$ Riga Stradins University, Faculty of Communication, Riga, Latvia
}

\begin{abstract}
The paper analyses the opinions of Latvian residents about the desired/ best conditions for person's death. Our intention was to use the concept of "good death" as it has been described in academic literature on the end of life to describe what circumstances of dying are preferred in Latvian population. A nationally representative survey of Latvian permanent residents $(n=1012)$ was conducted in October 2020. The obtained answers are analysed in different demographic groups, as well as in connection with other respondents' perceptions and values. The results of the study show that the possibility of dying in pain and suffering is a major concern for the majority of Latvian society, and a large percentage of people would like to leave their lives in sleep or sudden death. The results of the study also show people's desire to be in their homes at the time of death, to die in the presence of relatives. The survey shows a statistically significant relationship between people's perceptions of the desired/best conditions in which to die - "good death" and a range of demographic and social factors. The data of the study carried out provide new information on people's perceptions of death, highlighting differences in different socio-demographic groups.
\end{abstract}

Key words - good death, end of life, circumstances of dying, attitudes, survey.

\section{Introduction}

Philosophers, psychologists, writers, and sociologists at any time are looking for principles of happy end of life and brave and satisfied living in front of death. They are trying to identify and describe conditions needed for good death [1-3]. However, there is a lack of focus on exact explanation and no common understanding of what a good death is [4]. Formulations vary across times and cultures depending on value systems, ideologies and state of affairs in society and many of its sub-systems, including medical and social care and individual morality and responsibility. There is a difference in attitude towards death of religious people and non-believers [5], elderly people and young, people in suffering (either because of illness or lack of freedom, for example) and people conducting their lives in health and well-being.

The contemporary concept of "good death" gained wider attention in the academic community during the last 50-60 years. Despite different earlier uses (for example, in the context of conceptualising act of euthanasia [6] or in the context of history of sociology [7]) it was developed more concretely and focused in the context of palliative care and hospice movement 
$[6,7](.$.$) Therefore, its meaning is rooted in an ideology of systemic improvement of the qual-$ ity of life at the end of life (the fact that served as a base of certain criticism in sociological theory of death and dying accusing "good death" supporters and theorists in oversimplifying, lack of respect for individual life and privacy and bio-political attitudes [7]). A characteristic element of this approach is valuing of physical and emotional well-being at the end of life over the curating practices. However, the meaning of this concept is deeply subjective and based in cultural, generational, and other differences resulting in number of factors that should be taken into account to understand what is "good death" for particular individual in a given situation. There is a rich field of research focusing on those differences in meaning and factors influencing this meaning in the last decades. In the academic literature, "good death" is considered as the death in conditions that are in accord with clinical, cultural, and ethical standards and meet the requirements, needs and wishes of the patient, his or her family and caregivers [8]. Firstly, accents in importance of different needs and requirements for death to be "good" differ between all groups involved. An influential study conducted in 1999 showed that there is a gap between patients, family, and medical and other care givers across the USA - if all four groups think, for example, about pain and symptom management as a very important factor, patients more than others value mental awareness and coming to peace with God, while other factors examined like dying at home or life sustaining treatments or talking about meaning of death have received very diverse evaluation across all groups, death at home being generally least important [9]. The factor of staying at home (and receiving professional support) in contrast to moving to professional hospital or hospice institution is seen as ensuring emotional comfort rather ambivalently, so that researchers are calling for a more multifaceted approach [10] taking in account social and cultural differences between bereaved families and their living conditions.

This pointed out the need for studies taking in account diversity of factors influencing the requirements and expectancies for the end of life period and encouraged studies concentrating on national specifics [11-13] and cultural (and intercultural) aspects [14].

In spite of differences of initial theoretical and ideological approaches, methodologies of research and categories of respondents, what elements characterise the notion of "good death" in the discourse on palliative care and beyond? Smith names 11 principles of good death including knowing when death is coming, understanding of what can be expected, control, dignity and privacy, pain and symptom control, choice of the place of death (home/institution), access to information and expertise, spiritual or emotional support, access to hospice care in any location, control over who is present at the moment of death and time (including having time to say goodbye), ability to ensure respect for dying persons wishes, ability to leave vs. pointless life [15]. Krikorian, Maldonado and Pastrana based on review of literature on "good death" propose categories of analysis of this concept from the perspective of patients; their proposal includes model of 5 main personal attitudes (control of pain and symptoms, feeling a closure, being able to give to others, preparation for death, still being seen as a person), and 6 domains of factors that shape them (life circumstances, age, culture, religion, financial issues and disease) [6].

Studies mentioned here mostly analyze understanding of and attitude to the concept of "good death" from the perspective of one or more specific social groups - caregivers, medical staff, patients (of particular diseases like, for example, cancer), family members etc. The scope of this paper is significantly widened taking into account that culture and values in particular society can influence perception of the concept of "good death" in all sub-groups. Thus not only particular institutional or state policy can influence understanding of "good death", but overall cultural orientation (values, norms, traditions, rituals, history, common beliefs and symbolical levels of meaning) as well. Moreover, cultural orientation is needed to develop institutional and state policies ensuring "good death" conditions acceptable by 
everyone in society. The intention of this paper is to analyse the concept of "good death" in Latvian context in general, to find out what aspects are preferred to include in the concept of "good death" among Latvians, and to understand how these priorities are entangled in the social and cultural continuum - what factors in what ways have an impact on importance of particular aspects of "good death" in Latvian society. Based on above discussed theoretical conceptualizations and findings on particular groups in different countries a framework of indicators for circumstances of "good death" was formed to study the understanding of "good death" among population of Latvia. It includes painless death without suffering (including pain and symptom management), awareness / lack of awareness, control of place, time, people who are present at the time of death, situation (e.g. professional duty, heroic action etc.). As factors influencing understanding of "good death" and personal attitude to it several indicators were selected from different types of groups - age, occupation, religious and spiritual views (including attitude towards immortality), experience (e.g. first contact with death as well as attitude to euthanasia.

The aim of this paper is to analyze, present, and discuss results of this research to answer two research questions:

RQ1: What circumstances at the end of life are recognised as most (and least) important for a "good death" by Latvian population?

RQ2: What social, cultural, and demographic factors shape differences in perception of circumstances of "good death" by different groups of Latvian population? (The cultural factors include number of factors such as afterlife conceptions, religious views, ethical standpoints (including euthanasia etc.)).

\section{Material and methods}

The survey and analysis for this article was made in the context of wider research initiative - a project supported by the Latvian Research Council "Memento Mori: End of Life, Death and Imagined Afterlife in the Contemporary Latvian Life world". In this project wide diversity of different aspects connected to the conceptualisation of the end of life and death is analysed looking for the national level specifics of conceptualising death and end of life, with materials collected that allow finding out local and regional, but also generational and social differences. As a part of this research project, in October 2020, the nationally representative survey of Latvian permanent residents was conducted. In total, 1012 permanent residents of Latvia aged 18-75 were surveyed. The method used is Face-to-face interviews at the places of residence of respondents. We base our analysis on the data collected in the framework of this survey. Data were analysed and described using cross - tabulation, Kendall rank correlation, and Chi-Square test to find out relationships within data and include more factors that may give additional explanation to the patterns found.

\section{Results}

The findings of the study show that for most of the respondents, the possibility to die without pain and suffering is very important. It was stated by $66.5 \%$ of all respondents of the survey. For many respondents, dying in sleep seems like a good death (second most popular answer that makes $45.1 \%$ of all answers). The frequency of (mentioning) other answers is significantly lower, however, a relatively large proportion of respondents mentioned that they would like to die at home (26\%) and / or suddenly (16.7\%). Today in the presence of relatives has also been chosen in significant number of cases $(13.1 \%)$ and is more typical for some of the groups (see more detailed description further in the text), and almost similar amount of 
respondents (12\%) believe there is no good death. In a contrast to what has been discussed above, about the elements of concept of good death relatively small part of respondents (only $10.4 \%$ ) are interested in the control of what is happening in the end moments with even less attention paid to possibilities of dying in a happy moment (of life), heroic death or dying connected to professional duty (see Fig. 1).

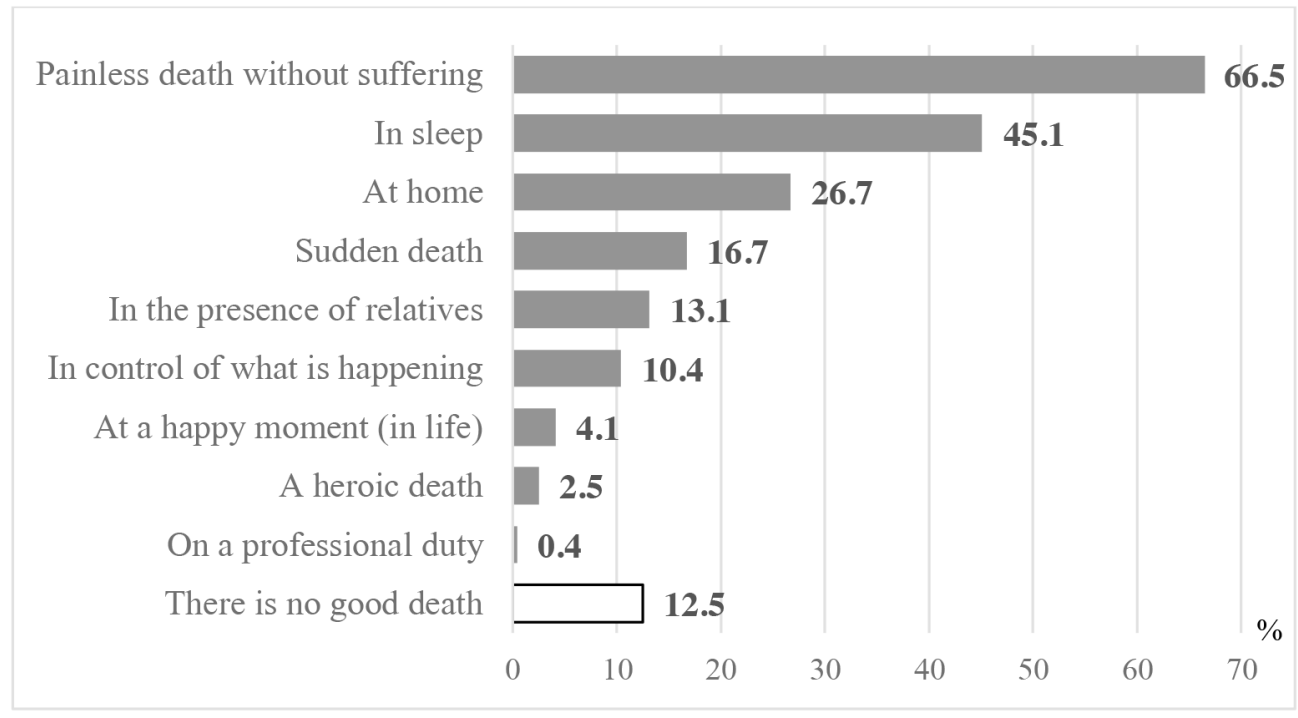

Figure 1. The circumstances in which it would be best for a person to die. $(N=1012$; "How / under what circumstances do you think it would be best for a person to die? Please mention up to 3 options".)

Social, demographic, and cultural factors must be taken into account to understand the choices of people in survey and to explain attitudes towards "good death" in particular groups of society. In the following part of the article, we will highlight the population groups of Latvian society for which the specific type of death seems particularly preferable (the frequency of mentioning is statistically significantly higher than in other population groups).

If we look at the respondents who noted that it would be best for a person to die without pain and suffering, it can be seen that statistically significantly (Chi-Square Test) more often they are Latvians, unemployed, living in a rural area, in Vidzeme, and they are more often Catholics than adhere to other denominations. These people are also significantly more likely to mention that they would not wish to be immortal. Their first memory of exposure to death is from preschool age. Thinking about their own death, they do not worry about missing many things after death, or inability to think and experience anything. They do not worry about pain or punishment after death or possibility of dying young, and of the disintegration of their bodies after death. When thinking about the end of life, they are mainly worried about the pain of dying, the fact that they will never be able to communicate with their people again; the feeling of loneliness and envy that they are dead.

If we look at the respondents who noted that it would be best for a person to die in sleep, more often they are, as before, Latvians, living in a rural area, with the first memory of exposure to death at preschool age, and would not care to be immortal. As well, they do not think that people will ever live forever. They are concerned about the brevity of life and fear the pain of death. It can also be noted that people who consider death in sleep to be a 
good form of death support euthanasia (if the person had expressed such a wish) and agree to transplantation of their organs after death.

Death at home was mentioned as a good way to die in all demographic groups by the same proportion of people, there are no statistically significant differences. Thinking about the end of life, they worry about the regret that they were not treated well enough when they were still alive and guilt for experiencing relief that they have died. They also do not support euthanasia.

Of the respondents, $16 \%$ mentioned dying suddenly as a good way to die. More often they are 64-75 years old, retired, live in Zemgale region and would like to be immortal. These people do not worry about the fact that they will never be able to communicate with other people again.

As in the case of sudden death, death in the presence of relatives was mentioned as a good way to die more often by the elderly. The opportunity to die in the presence of relatives is more important for ethnic Latvians, people in Vidzeme and Latgale regions, as well as Latvian citizens. Thinking about the death, these people worry about the fact that they will never be able to communicate with people again, that they will have to grow old without people who had died earlier and the feeling of loneliness.

In control of what is happening - is a choice of people with higher education and of those who are socially active. They agree to donate their organs for transplantation, but only to their relatives.

Those who preferred to die at a happy moment in life are most often males, unbelievers or indifferent to religion, atheists, residents of Vidzeme regions, and report higher incomes.

To die a heroic death seems appealing to men, young people, with average personal income, unmarried and Atheists. These people want to be immortal. They do not worry about body's physical decay in slow death and agree to donate their organs for transplantation, but only to their relatives.

On a professional duty, was an answer of only 4 people, and statistically significant demographic groups are not marked here.

A relatively large proportion $-12.5 \%$ of respondents mentioned that they do not think there is such thing as a good death. It is important to emphasize that these are mostly people who have not had a personal encounter with death so far.

The following figure shows the most often mentioned answers and combinations of circumstances in which it would be best for a person to die. The question "How / under what circumstances do you think it would be best for a person to die?" was a multi-answer question, respectively, respondents could mention one or more answers, or answer that there is no good death. As mentioned in this article, the possibility to die without pain and suffering is very important for the majority of the Latvian population (mentioned by $66 \%$ of respondents). The importance of this aspect is also confirmed by the fact that for a large part of the respondents (14.1\%) this was the only chosen answer (see Fig. 2). Next, the frequency of mention is followed by a combination of answers ("without pain and suffering + in sleep" and "without pain and suffering + in sleep+ at home"), followed by death in sleep (mentioned as the only answer by $67 \%$ of respondents).

In-depth analysis was able to identify positive correlations between the following circumstances in which it would be best for a person to die: in sleep and without pain and suffering ( $r=.08, p<.001)$, at home and without pain and suffering $(r=.10, p<.001)$, in sleep and suddenly $(r=.08, p<.005)$, to die a heroic death and on a professional duty $(r=.09, p<$ $.001)$, on a professional duty and at a happy moment of life $(r=.23, p<.001)$; and negative correlations between the following circumstances: to die without pain and suffering and to die a heroic death $(r=-.07, p<.005)$, in sleep and in control of what is happening $(r=-.07$, $p<.005)$, in sleep and in the presence of relatives $(r=-.17, p<.001)$, in the presence of 


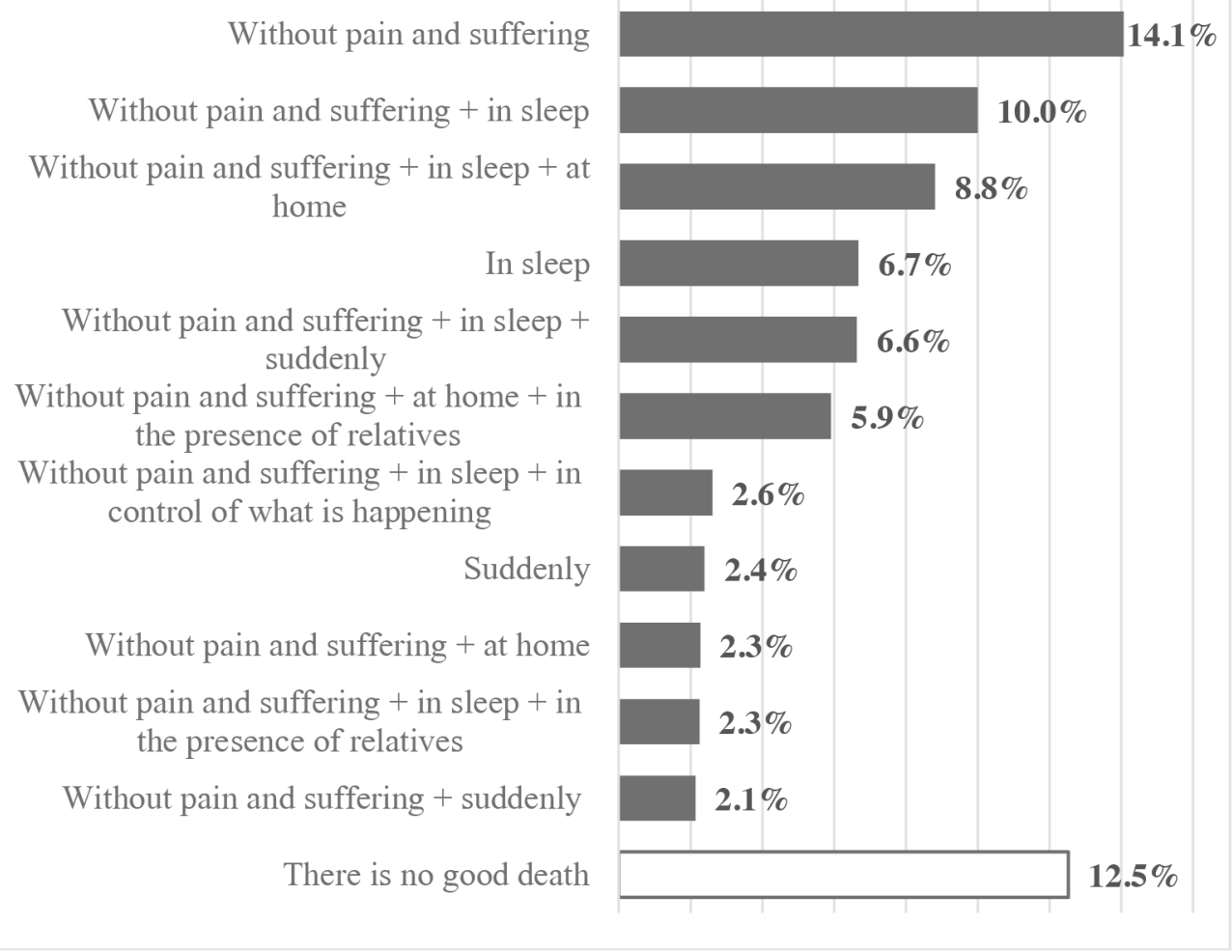

Figure 2. The most often mentioned answers and combinations of circumstances in which it would be best for a person to die. $(N=1012$.)

relatives and suddenly $(r=-.10, p<.001)$, at home and suddenly $(r=-.16, p<.001)$ (see Fig. 3).

\section{Conclusions}

The results of the study show that the possibility of dying in pain and suffering is a major concern for the majority of people in Latvian society. A large percentage of people would like to leave their lives in sleep or by sudden death. So, the answer of the first research question (RQ1) is: the most important aspect of a "good death" for the majority of Latvian people is lack of suffering and pain. In the survey, it was chosen by $66.5 \%$ of all respondents, and importance of dying without pain and suffering is even more accented by the fact that of all possible combinations of answers biggest number $-14 \%$ of all respondents - marked this answer only. The least number of people connect "good death" with professional duties. From the analysis of positive and negative correlations one can see that the society can be divided into three types of attitude - (a) those who would like to die without pain and suffering, in sleep and suddenly, (b) those who understand "good death" as death without pain and suffering and at home, and (c) those who see "good death in more abstract way - connect it to heroism, professional duty and/or happy moment in life.

It signalizes that Latvians in their majority are tended to see the end of life with uncertainty, concern and fear of suffering and that most of the people in Latvia are rather tended to 


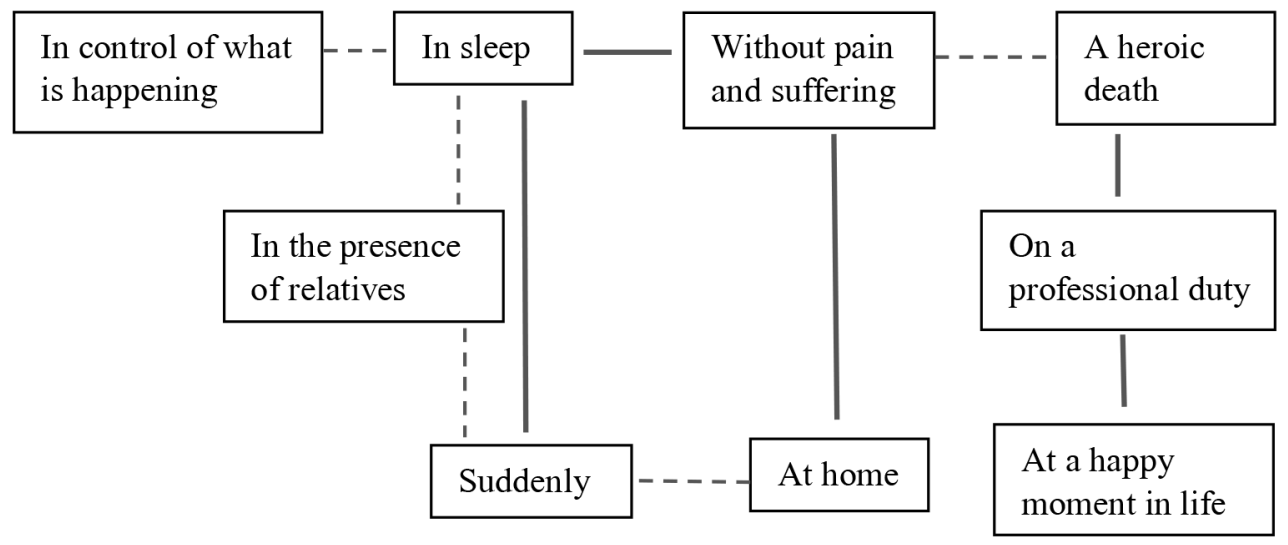

positive correlation

- - - negative correlation

Figure 3. The correlation of circumstances in which it would be best for a person to die. $(N=1012$.)

avoid to die in full awareness of happening (with possible pain and suffering). They are not in their majority so much afraid of suffering after their death and are not aimed at immortality (even if they are belonging to one of the Christian confessions). The relatively little number of respondents have expressed their interest to maintain control over the happening in the moment of dying, and non significant number of people connect "good death" at the end of life with professional duty, heroic acts or experience of happy last moments. They do rather think that "good death" is a death in sleep and possibly at home. It is rather important for people to stay at home for "good death" - this is the third most popular aspect of circumstances of dying for Latvian people and is represented almost equally in all groups of respondents. Especially, older generations think that dying surrounded by relatives and beloved ones is an important element of "good death" even if they feel sorry for those left and lost relationships with people. There is also an interesting difference between those who would like to die at home and those who would prefer death in sleep. The first group are in their majority against, but the latter support euthanasia.

To answer the second research question (RQ2) of this paper, the analysis was looking for statistically significant relationships between people's perceptions of the desired/best conditions in which to die and a range of demographic and social factors as well as some cultural and subjective factors that could influence their understanding of the "good death". Demographic factors (as mentioned higher) plays different rather a minor roles. However, some links have strong appearance. One of the most explicit tendencies shows that the group with early significant/memorable contact with death (at the 1-6 years of age) correlates with someone's own desire to die without pain and suffering or in sleep, in other words - coming in contact with somebody's death before school age might lead to bigger avoidance of pain and suffering when dying. Some social or even economic factors have a place. For example, unemployed people are the part of respondents that care most clearly about painless death. Those who prefer sudden death are more often wishing immortality then others and are more often belonging to the older age group. In general, elderly people expressed a desire to die a sudden death or to be in the presence of relatives at the time of death. Young men without family who are not believers most clearly are representing the small group of respondents that think of a heroic death as a "good death". Nonetheless the control over death is not mostly 
preferred answer in the survey, one can notice that maintaining control over what is happening at the time of death is more important for people with higher education and those who have been socially active in life. The more wealthy people, males and those who describe themselves as not believers are tended more than others towards dying in a happy moment of life, even if in general this is not very popular aspect in people's conceptualisations of "good death".

\section{References}

[1] G. Walters, Palliat. Med. 18(5), 404-408 (2004)

[2] A. Hupp, A Psychological and Philosophical Understanding of Death: An Analysis of Platonic and Epicurean Philosophy in Modern America, 32 (Honors Bachelor of Arts, Xavier University, Cincinnati, 2017)

[3] E. Montaguti, R.J. Jox, E. Zwick, M. Picozzi, Medicina Hist. 2 (2018)

[4] S.M. Campbell, Ethical Theory Moral Pract. 23, 607-623 (2020)

[5] L. Bovens, in R. Green (ed.), Theories of Hope: Exploring Alternative Affective Dimensions of Human Experience (Lexington Press, Lanham 2018)

[6] A. Krikorian, C. Maldonado, T. Pastrana. J. Pain Symptom Manag 59(1), 152-164 (2020)

[7] B. Hart, P. Sainsbury, S. Short. Mortality (Abingdon) 3(1), 65-77 (1998)

[8] M.J. Field, C.K. Cassel (ed.) Approaching Death: Improving Care at the End of Life (National Academy Press, Washington, 1997)

[9] K.E. Steinhauser, N.A. Christakis, E.C. Clipp, M. McNeilly, L. McIntyre, J.A. Tulsky. Jama 284(19), 2476-2482 (2000)

[10] J.M. Teno, B.R. Clarridge, V. Casey, et al. Jama 291(1), 88-93 (2004)

[11] L. Kastbom, A. Milberg, M. Karlsson. Support Care Cancer 25(3), 933-939 (2017)

[12] Y.H. Yun et al. Support Care Cancer 26(10), 3479-3488 (2018)

[13] E.T. Lewis, et al. Health Expect 22(3), 405-414 (2019)

[14] M. Masanori, Y. Kuwama, T. Ashikaga, H.A. Parsons, M. Miyashita. J. Pain Symptom Manag 55(1), 31-38 (2018)

[15] R. Smith, BMJ 320, 129-130 (2000)

\section{Appendixes}

Table 1. Demographics groups used in analyse.

\begin{tabular}{|l|l|}
\hline Group & Subgroup \\
\hline \multirow{2}{*}{ GENDER } & Male \\
\cline { 2 - 2 } & Female \\
\hline AGE & $18-24$ years \\
\hline
\end{tabular}


Table 1. Continued.

\begin{tabular}{|c|c|}
\hline & $25-34$ years \\
\hline & $35-44$ years \\
\hline & $45-54$ years \\
\hline & 55-63 years \\
\hline & $64-75$ years \\
\hline MARITAL STATUS & Married or living with a partner \\
\hline & Divorced or not living with husband/wife \\
\hline & Single \\
\hline & Widowed \\
\hline LANGUAGE SPOKEN IN THE & Latvian \\
\hline FAMILY & Russian \\
\hline & Other \\
\hline EDUCATION & Primary \\
\hline & Secondary/secondary professional \\
\hline & Higher \\
\hline MAIN OCCUPATION & Top or medium level manager \\
\hline & Clerk, specialist (not physical work) \\
\hline & Worker (physical work) \\
\hline & Self-employed, individual work \\
\hline & Retired \\
\hline & Schoolchild, student \\
\hline & Homemaker, parental leave \\
\hline & Unemployed \\
\hline AVERAGE MONTHLY NET & Low (250 EUR and less) \\
\hline INCOME PER ONE FAMILY & Medium low (251-349 EUR) \\
\hline MEMBER (Quintiles) & Medium (350-410 EUR) \\
\hline & Medium high (411-600 EUR) \\
\hline & High (601 EUR and more) \\
\hline & Hard to say \\
\hline PERSONAL AVERAGE & Low (330 EUR and less) \\
\hline MONTHLY NET INCOME & Medium low (331-450 EUR) \\
\hline (Quintiles) & Medium (451-690 EUR) \\
\hline & Medium high (691-1000 EUR) \\
\hline & High (1001 EUR and more) \\
\hline & Hard to say \\
\hline CHILDREN UP TO AGE 18 & Yes \\
\hline LIVING IN & No \\
\hline & Hard to say \\
\hline HOUSEHOLD SIZE & One person \\
\hline & Two persons \\
\hline & Three persons \\
\hline & Four or more persons \\
\hline REGION & Riga \\
\hline & Vidzeme \\
\hline & Kurzeme \\
\hline & Zemgale \\
\hline & Latgale \\
\hline
\end{tabular}


Table 1. Continued.

\begin{tabular}{|l|l|}
\hline TYPE OF SETTLEMENT & Riga \\
\cline { 2 - 2 } & Other city \\
\cline { 2 - 2 } & Rural area \\
\hline
\end{tabular}

Table 2. Comparison of the sample achieved with population statistics.

\begin{tabular}{|c|c|c|c|c|}
\hline & $\begin{array}{l}\text { General } \\
\text { population } \\
\text { (thousand } \\
\text { people) }\end{array}$ & $\begin{array}{l}\text { Number of } \\
\text { respondents in } \\
\text { the sample (\%) } \\
\text { before weighing }\end{array}$ & $\begin{array}{l}\text { Number of } \\
\text { respondents in } \\
\text { the sample (\%) } \\
\text { after weighing }\end{array}$ & $\begin{array}{l}\text { Data of the } \\
\text { Office of } \\
\text { Citizenship } \\
\text { and Migration } \\
\text { Affairs } \\
\text { (at 27.01.20.) }\end{array}$ \\
\hline TOTAL & 1527 & 100.0 & 100.0 & 100.0 \\
\hline \multicolumn{5}{|l|}{ REGION } \\
\hline Rīga & 511 & 33.3 & 33.5 & 33.5 \\
\hline Pierīga & 291 & 19.2 & 19.1 & 19.1 \\
\hline Vidzeme & 146 & 9.4 & 9.5 & 9.5 \\
\hline Kurzeme & 189 & 12.6 & 12.4 & 12.4 \\
\hline Zemgale & 179 & 11.7 & 11.8 & 11.8 \\
\hline Latgale & 211 & 13.8 & 13.8 & 13.8 \\
\hline \multicolumn{5}{|l|}{ GENDER } \\
\hline Male & 737 & 47.9 & 48.3 & 48.3 \\
\hline Female & 790 & 52.1 & 51.7 & 51.7 \\
\hline \multicolumn{5}{|l|}{ NATIONALITY } \\
\hline Latvian & 898 & 58.8 & 58.8 & 58.8 \\
\hline Other & 629 & 41.2 & 41.2 & 41.2 \\
\hline \multicolumn{5}{|l|}{ AGE GROUP } \\
\hline 18 - 24 y.o. & 130 & 10.0 & 8.5 & 8.5 \\
\hline 25 - 34 y.o. & 296 & 18.3 & 19.4 & 19.4 \\
\hline $35-44$ у.о. & 295 & 18.3 & 19.4 & 19.4 \\
\hline 45 - 54 y.o. & 290 & 19.6 & 19.0 & 19.0 \\
\hline $55-63$ у.о. & 266 & 16.1 & 17.4 & 17.4 \\
\hline $64-75$ у.о. & 250 & 17.7 & 16.4 & 16.4 \\
\hline \multicolumn{5}{|c|}{ WORKING STATUS } \\
\hline Employees & & 64.9 & 66.3 & \\
\hline Non-employees & & 35.1 & 33.7 & \\
\hline \multicolumn{5}{|l|}{ EDUCATION } \\
\hline Elementary & & 10.3 & 9.9 & \\
\hline Secondary & & 25.4 & 25.0 & \\
\hline $\begin{array}{l}\text { Secondary profes- } \\
\text { sional }\end{array}$ & & 37.6 & 38.0 & \\
\hline Higher & & 26.7 & 27.1 & \\
\hline \multicolumn{5}{|l|}{ CITIZENSHIP } \\
\hline Latvian citizenship & & 87.8 & 87.9 & \\
\hline $\begin{array}{l}\text { Respondents with- } \\
\text { out Latvian citizen- } \\
\text { ship }\end{array}$ & & 12.2 & 12.1 & \\
\hline
\end{tabular}

Data were weighted by characteristics: region, gender, nationality, age. 